\title{
A tetrameric inhibitor of insect $\alpha$-amylase from barley
}

\author{
Rosa Sanchez-Monge, Luis Gomez, Francisco Garcia-Olmedo and Gabriel Salcedo \\ Departamento de Bioquímica. ETS Ingenieros Agrónomos-UPM, 28040 Madrid, Spain
}

\begin{abstract}
A tetrameric inhibitor that is active against $\alpha$-amylase from the larvae of the insect Tenebrio molitor, but inactive against the enzyme from human saliva and against the endogenous one, has been described in barley endosperm. The subunits of the inhibitor have been identified as the previously characterized proteins CMa, $\mathrm{CMb}$ and $\mathrm{CMd}$, of which only CMa was inhibitory by itself.
\end{abstract}

$\alpha$-Amylase inhibitor (Barley) Subunit association Multi-gene family Endosperm protein Chloroform-methanol soluble protein

\section{INTRODUCTION}

Protein inhibitors of heterologous $\alpha$-amylases have been found in many seeds [1-3] and those from wheat endosperm have received particular attention $[1,2]$. Fractionation of the wheat inhibitors by gel filtration in the absence of dissociating agents yields three families of isoinhibitors with apparent molecular masses of 12,24 and $60 \mathrm{kDa}$, which respectively correspond to monomeric, dimeric and tetrameric forms [4]. The first two families have been extensively characterized [1,5-8], and we have presented evidence that their components are encoded in wheat and barley by disperse multi-gene families that also encode trypsin inhibitors and subunits with no apparent in vitro activities [9-14]. A high proportion of the members of this group of proteins can be selectively extracted by chloroform/methanol mixtures and have been designated CM-proteins (see [2]). Less information is available concerning the tetrameric inhibitors [15] and, in particuiar, their subunits have not been purified and characterized, and there is no direct evidence that they belong to the same homologous family as those of the monomeric and dimeric inhibitors. In barley, only one subunit of this protein family has been found to inhibit insect $\alpha$-amylase [12]. We now report a tetrameric barley inhibitor, which is specific for insect $\alpha$-amylase and is composed of the previously described active subunit and of subunits that are not inhibitory by themselves.

\section{MATERIALS AND METHODS}

A crude inhibitor preparation was obtained from barley endosperm (Hordeum vulgare cv. Bomi) essentially as described for wheat [15]: the ground endosperm was extracted with $150 \mathrm{mM}$ $\mathrm{NaCl}$, and the salt extract was precipitated with $50 \%$ saturated $\left(\mathrm{NH}_{4}\right)_{2} \mathrm{SO}_{4}$, suspended in water, dialysed and lyophilized. Gel filtration was carried out on Sephadex G-100, using $100 \mathrm{mM}$ ammonium acetate as elution buffer (225 $\mathrm{mg}$ of protein; $2.5 \times$ $90 \mathrm{~cm}$ column; $25 \mathrm{ml} / \mathrm{h} ; 8 \mathrm{ml}$ fractions). Appropriate aliquots of the eluted fractions were assayed for their inhibitory activities against the $\alpha$ amylases from the larvae of the insect Tenebrio molitor and from human saliva, as well as against the barley enzyme. Endogenous $\alpha$-amylases were 


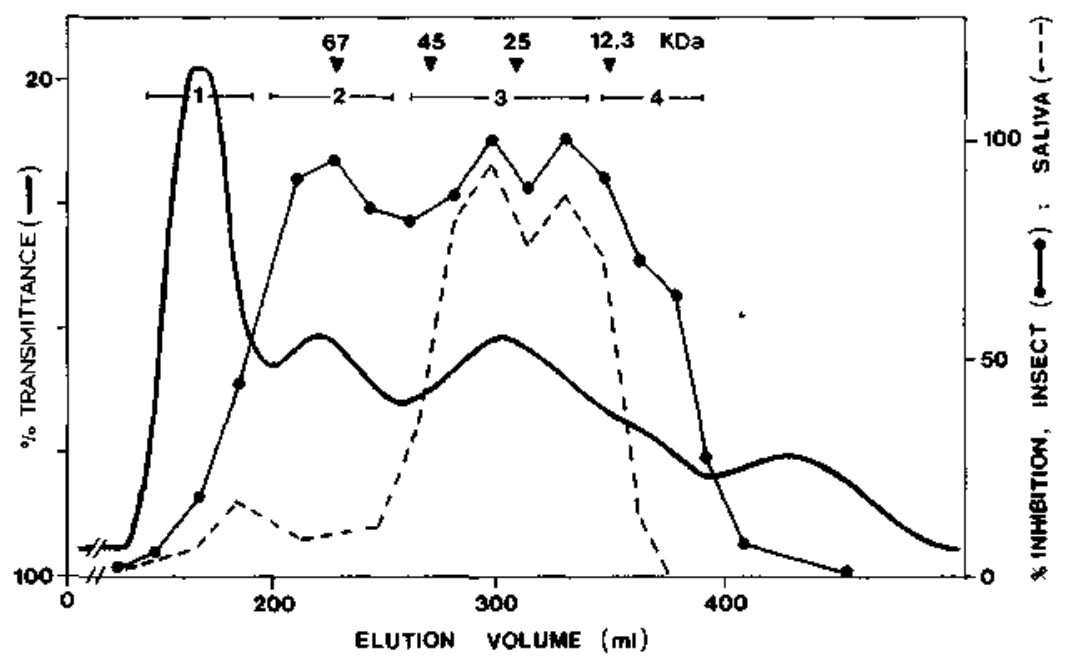

Fig.1. Gel filtration on Sephadex G-100 of proteins extracted from barley endosperm with $150 \mathrm{mM} \mathrm{NaCl}$ and precipitated with $50 \%$ saturated $\left(\mathrm{NH}_{4}\right)_{2} \mathrm{SO}_{4}$. Fractions were also tested against barley $\alpha$-amylase and no inhibitory activity was detected (not represented). Bovine serum albumin (67 kDa), ovalbumin (45 kDa), chymotrypsinogen

(25 kDa), and cytochrome $c(12.3 \mathrm{kDa})$ were used to calibrate the column.

inactivated by heating for $40 \mathrm{~min}$ at $60^{\circ} \mathrm{C}$ and the tests were carried out as in a previous report [12]. Proteins $\mathrm{CMa}, \mathrm{CMb}$ and $\mathrm{CMd}$ were purified as described $[16,17]$. SDS-PAGE was performed according to Laemmli [18]. Two-dimensional electrophoresis, IEF ( $\mathrm{pH} 4-9$ or 5-8) $\times$ SGE (pH 3.2), was carried out as in [9], except that $6 \mathrm{M}$ urea was omitted in the first dimension when indicated and that, in these cases, the protein samples were included in the polymerization mixtures.

\section{RESULTS AND DISCUSSION}

A crude inhibitor preparation, obtained from barley endosperm by salt extraction and $\left(\mathrm{NH}_{4}\right)_{2} \mathrm{SO}_{4}$ precipitation, was subjected to gel filtration as indicated in fig. 1. Three peaks of inhibitory activity against the $\alpha$-amylase of the insect T. molitor were found and their apparent molecular masses were respectively similar to those assigned to the monomeric, dimeric and tetrameric inhibitors of wheat [4]. Activity against salivary $\alpha$ amylase was also found in the peaks corresponding to the monomeric and dimeric forms, whereas the activity of the tetrameric form seemed to be specific for the insect enzyme (fig.1). Proteins from the four fractions indicated in fig.1 were separated by SDS-PAGE, as shown in fig.2. Two prominent bands, which only appeared in fraction 2 , had apparent molecular masses in the range of 12-15 kDa, as expected for the subunits of the

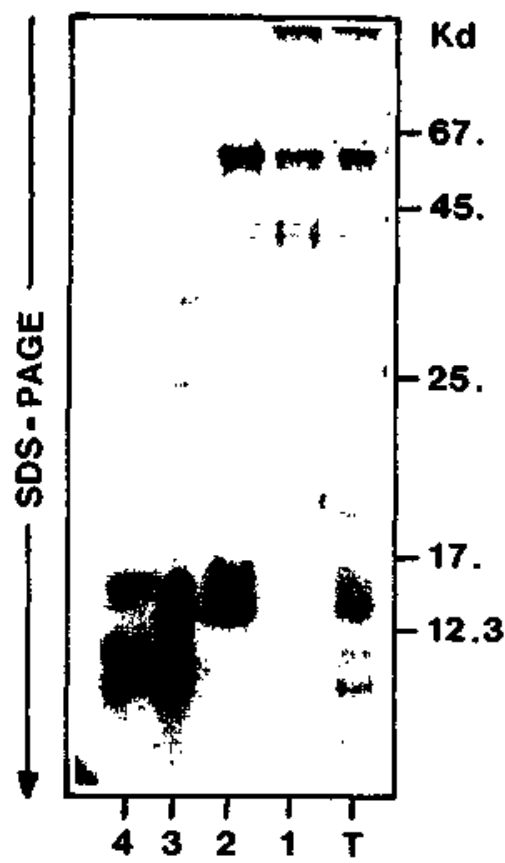

Fig.2. SDS-PAGE of total extract (T) and of fractions $1-4$, which were pooled as indicated in fig. 1 . 
tetrameric inhibitors [15]. These proteins were separated from the high-molecular-mass components common to fractions 1 and 2 by gel filtration under dissociating conditions (not shown) and further analysed by two-dimensional electrophoresis, as shown in fig.3B. Three components that co-migrated with pure samples of the previously characterized proteins $\mathrm{CMa}, \mathrm{CMb}$ and CMd were observed, which suggested that these proteins were indeed the subunits of the tetrameric inhibitors. Fig.3C shows a two-dimensional fractionation of proteins corresponding to fraction 2, in which $6 \mathrm{M}$ urea has been omitted as dissociating agent in the first dimension and the high-
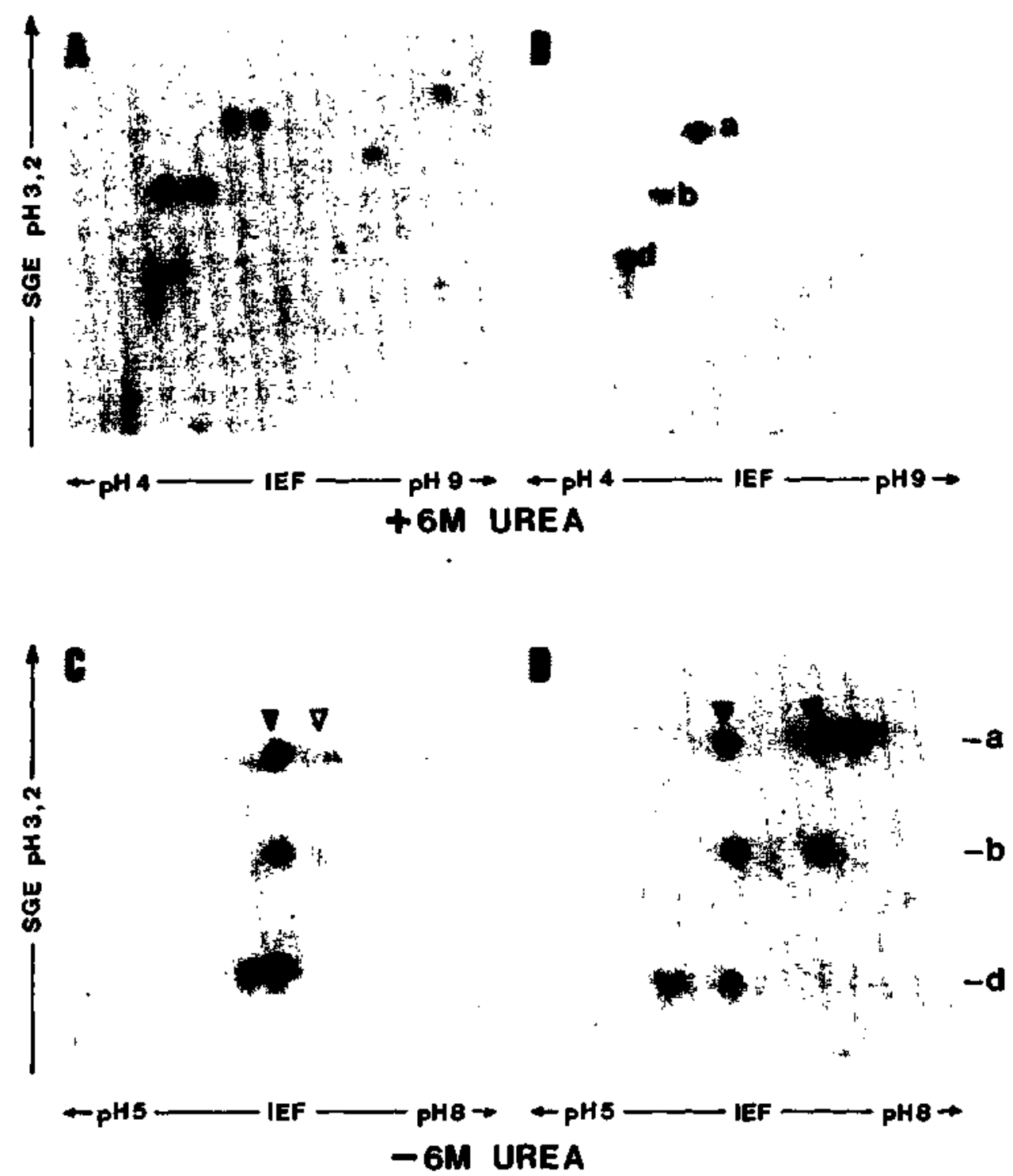

Fig.3. Two-dimensional fractionation by combined IEF (pH 4-9 or 5-8) $\times$ SGE (pH 3.2). (A) Total extract. (B) Lowmolecular-mass proteins from fraction 2 of fig.1. (C) Fraction 2. (D) Mixture of the purified proteins $\mathrm{CMa}, \mathrm{CMb}$ and CMd. (A,B) Dissociating conditions (6 M urea) were used in the 1st dimension. (C,D) Non-dissociating conditions; associations were indicated by arrowheads $(\nabla, \nabla)$; mobilities in the 2nd dimension of proteins $\mathrm{CMa}, \mathrm{CMb}$, and $\mathrm{CMd}$ are indicated $(a, b, d)$ at the right side of the figure. IEF was carried out for 1 extra hour in $D$ with respect to $C$. 
molecular-mass components do not penetrate into the gel. Under these conditions, a complex pattern is observed which indicates that associations occur, the most abundant of which includes the three proteins. A similar pattern is obtained when the three purified proteins are mixed (fig.3D), indicating that the association can be reconstituted in vitro. As reported [12], protein CMa was active against insect $\alpha$-amylase, whereas $\mathrm{CMb}$ and $\mathrm{CMd}$ were inactive by themselves. In view of the associations shown in fig.3, the inhibitory properties of different mixtures of these proteins were investigated as summarized in fig.4. For a given amount of protein, there was no significant difference between the activities of all the binary mixtures, including the mixture of the two inactive subunits $(\mathrm{CMb}+$ $\mathrm{CMd}$ ), and that of CMa by itself, whereas the mixture of the three proteins was about twice as active as $\mathrm{CMa}$ or the binary mixtures. Of all the interactions demonstrated in this experiment, that of $\mathrm{CMa}$ with the other two proteins and, to a lesser extent, that of $\mathrm{CMa}$ with $\mathrm{CMb}$ seem to be the only significant ones in vivo, based on the observations presented in fig.3.

The gene encoding $\mathrm{CMa}$ has been located in chromosome 1 of barley (homologous to group 7 of wheat), and the genes for $\mathrm{CMb}$ and $\mathrm{CMd}$ have

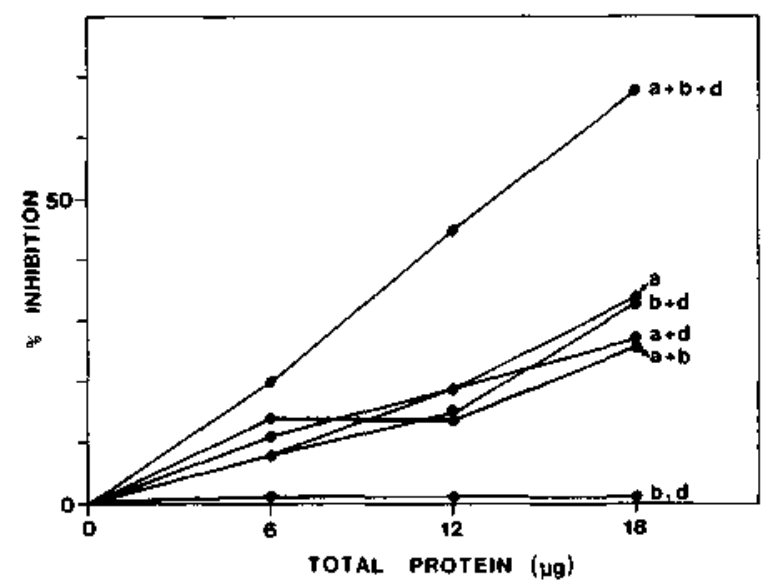

Fig.4. Inhibition of $\alpha$-amylase from larvae of Tenebrio molitor by purified proteins $\mathrm{CMa}, \mathrm{CMb}, \mathrm{CMd}$ and their mixtures. Equal amounts of each of the indicated proteins were used in the mixtures. All tests were carried out with approx. 2 units of $\alpha$-amylase ( 1 unit defined as the amount of enzyme required to produce the reducing equivalents of $1 \mathrm{mg}$ of maltose in $20 \mathrm{~min}$ ). been assigned to chromosome $4[11,12]$. In wheat, we have shown that this multi-gene family is dispersed over chromosomes of groups $3,4,6$, and $7[9,14]$ and have assigned genes for the monomeric and dimeric inhibitors to chromosomes of groups 3 and 6 [13]. The identification of proteins encoded in chromosomes 1 and 4 of barley as components of the tetrameric inhibitor suggested that proteins encoded in chromosomes of groups 4 and 7 of wheat, which were not active by themselves [14], might be the components of the wheat tetrameric inhibitors. Preliminary experiments seem to confirm this hypothesis (unpublished). We have previously observed that the members of this protein group that correspond to chromosomes of groups 4 and 7 (1 in barley) are more effectively extracted by chloroform-methanol mixtures than those associated with chromosomes of groups 3 and 6 because of their hydrophobicity $[16,19]$, a property that might be related to the tetrameric interactions.

It has been reported that crude prolamin preparations are inhibitory for $\alpha$-amylases [1], and indeed certain domains of the prolamins show a weak homology with the CM-proteins $[20,21]$, but we have shown that significant amounts of CMproteins are present in prolamin preparations obtained by different procedures $[19,22]$, which in view of the present results is a more plausible explanation for the above observation.

\section{ACKNOWLEDGEMENTS}

The technical assistance of J. Garcia-Guijarro and grant no.2022/83 from the Comisión Asesora de Investigación Científica y Técnica are gratefully acknowledged. L.G. is the recipient of a scholarship from the Ministerio de Educación y Ciencia.

\section{REFERENCES}

[1] Buonocore, V., Petrucci, T. and Silano, V. (1977) Phytochemistry 16, 811-820.

[2] Garcia-Olmedo, F., Carbonero, P. and Jones, B.L. (1982) in: Advances in Cereal Science and Technology (Pomeranz, Y. ed.) vol.V, pp.1-47, AACC, St. Paul, MN.

[3] Shewry, P.R. and Miflin, B.J. (1985) in: Advances in Cereal Science and Technology (Pomeranz, Y. ed.) vol.VII, pp.1-83, AACC, St. Paul, MN. 
[4] Deponte, R., Parlamenti, R., Petrucci, T., Silano, V. and Tomasi, M. (1976) Cereal Chem. 53, 805-819.

[5] Silano, V. and Zahnley, J.C. (1978) Biochim. Biophys. Acta 533, 181-185.

[6] O'Connor, C.M. and McGeeney, K.F. (1981) Biochim. Biophys. Acta 658, 387-396.

[7] Kashlan, N. and Richardson, M. (1981) Phytochemistry 20, 1781-1784.

[8] Maeda, K., Kakabayashi, S. and Matsubara, H. (1985) Biochim. Biophys. Acta 828, 213-221.

[9] Fra-Mon, P., Salcedo, G., Aragoncillo, C. and Garcia-Olmedo, F. (1984) Theor. Appl. Genet. 69, 167-172.

[10] Shewry, P., Lafiandra, D., Salcedo, G., Aragoncillo, C., Garcia-Olmedo, F., Lew, E.J.-L., Dietler, M.D. and Kasarda, D.D. (1984) FEBS Lett. 175, 359-363.

[1]] Salcedo, G., Fra-Mon, P., Molina-Cano, J.L., Aragoncillo, C. and García-Olmedo, F. (1984) Theor. Appl. Genet. 68, 53-59.

[12] Barber, D., Sanchez-Monge, R., Mendez, E., Lazaro, A., García-Olmedo, F. and Salcedo, G. (1986) Biochim. Biophys. Acta 869, 115-118.

[13] Sanchez-Monge, R., Barber, D., Mendez, E., Garcia-Olmedo, F, and Salcedo, G. (1986) Theor. Appl. Genet. 72, 108-113.
[14] Barber, D., Sanchez-Monge, R., García-Olmedo, F., Salcedo, G. and Mendez, E. (1986) Biochim. Biophys. Acta, in press.

[15] Buonocore, V., De Biasi, M.-G., Giardina, P., Poerio, E. and Silano, V. (1985) Biochim. Biophys. Acta 831, 40-48.

[16] Salcedo, G., Sanchez-Monge, R. and Aragoncillo, C. (1982) J. Exp. Bot. 33, 1325-1331.

[17] Lazaro, A., Barber, D., Salcedo, G., Mendez, E. and García-Olmedo, F. (1985) Eur. J. Biochem. $149,617-623$.

[18] Laemmli, V.K. (1970) Nature 62, 256-263.

[19] Rodriguez-Loperena, M.A., Aragoncillo, C., Carbonero, P. and Garcia-Olmedo, F. (1975) Phytochemistry 14, 1219-1223.

[20] Kreis, M., Forde, B.G., Rahman, S., Miflin, B.J. and Shewry, P.R. (1985) J. Mol. Biol. 183, 499-502.

[21] Paz-Ares, J., Ponz, F., Rodriguez-Palenzuela, P., Lazaro, A., Hernández-Lucas, C., Garcia-Olmedo, F. and Carbonero, P. (1986) Theor. Appl. Genet. 71, 842-846.

[22] Salcedo, G., Sanchez-Monge, R., Argamenteria, A. and Aragoncillo, C. (1980) Plant Sci. Lett. 19, 109-119. 